University of South Carolina

Scholar Commons

8-7-2013

\title{
Cutting Carbon, Take Two: A Brief Guide to Federal Electricity- Sector Climate Policy without Cap-and-Trade
}

\author{
Nathan Richardson \\ University of South Carolina - Columbia, richarnd@law.sc.edu \\ Joshua Linn \\ University of Maryland at College Park
}

Follow this and additional works at: https://scholarcommons.sc.edu/law_facpub

Part of the Environmental Law Commons

\section{Recommended Citation}

Joshua Linn and Nathan Richardson, Cutting Carbon, Take Two: A Brief Guide to Federal Electricity-Sector Climate Policy without Cap-and-Trade, 35 Applied Economic Perspectives and Policy, 377 (2013).

This Article is brought to you by the Law School at Scholar Commons. It has been accepted for inclusion in Faculty Publications by an authorized administrator of Scholar Commons. For more information, please contact digres@mailbox.sc.edu. 


\title{
Featured Article
}

\section{Cutting Carbon, Take Two: A Brief Guide to Federal Electricity-Sector Climate Policy without Cap-and-Trade}

\author{
Joshua Linn* and Nathan Richardson \\ Joshua Linn is a Fellow at Resources for the Future. Nathan Richardson is a Resident \\ Scholar at Resources for the Future.
}

*Correspondence may be sent to: linn@rff.org.

Submitted 8 April 2013; accepted 11 June 2013.

\begin{abstract}
This paper explores federal policies, other than a carbon price, for reducing emissions from the electric power sector. These policies fall into two major categories: policies that encourage the development of non- or low-emitting energy sources, and regulatory policies under existing legal authority (primarily the Clean Air Act). The paper provides an overview of policy options and a few concrete proposals, along with a summary of insights from economists on their advantages and disadvantages. Economists generally disfavor investment subsidies, but comparing other policy options, including regulatory approaches, technology mandates, and production subsidies, is complex. Excluding existing clean generation from incentive policies is tempting but can lead to perverse outcomes.
\end{abstract}

Key words: Greenhouse gas policy, Carbon price, Renewable portfolio standard, Feed-in tariff, Production tax credit, Investment tax credit, Clean Air Act.

JEL codes: L94, Q54.

The U.S. electricity sector accounts for about $40 \%$ of the country's total carbon dioxide $\left(\mathrm{CO}_{2}\right)$ emissions, and is widely believed to contain some of the lowest-cost opportunities for reducing emissions. To cut emissions from this sector or the wider economy, most economists (e.g., Krupnick et al. 2010; Parry and Williams 2011) favor a well-designed carbon price (cap-and-trade or a carbon tax). But the failure of climate legislation in the U.S. Senate in 2010, and the current political makeup of the U.S. House of Representatives both indicate that a federal carbon price is extremely improbable in the near future. In its place, the U.S. Environmental Protection Agency (EPA) is in the process of regulating emissions under the existing Clean Air Act (CAA), and some states have moved ahead with

(C) The Author(s) 2013. Published by Oxford University Press, on behalf of Agricultural and Applied Economics Association. All rights reserved. For permissions, please email:

journals.permissions@oup.com. 
state- or regional-level policies, some of which include carbon prices. ${ }^{1}$ Federal legislation is still possible too, so long as one is willing to look beyond a carbon price.

In fact, a broader set of policies both in use and under consideration target investment in clean electricity technology without using an emissions price. These policies include technology mandates (such as renewable portfolio standards), feed-in tariffs, subsidies for investment and generation, and loan guarantees. One example is President Obama's proposal for a clean energy standard in his 2011 State of the Union Address, which called for a share of national electricity generation to come from "clean" sources that emit less $\mathrm{CO}_{2}$ for the electricity they generate than the most carbonintensive, or "dirtiest," source of electricity, coal without carbon capture (a definition of clean vs. dirty sources that we will use here).

There has been an intense debate over this and other recent proposals for new clean electricity policies, as well as over whether existing subsidies to renewable technologies should continue given the size of the federal deficit. The aim of this paper is to take a figurative step back and, without focusing on the details of any specific policy or proposal, lay out the fundamental differences among policy options for reducing carbon emissions from the electric power sector without a carbon price. ${ }^{2}$ We will first briefly discuss regulatory options under existing law (the CAA), before analyzing three types of policies aimed at creating incentives for clean energy: technology mandates (such as renewable portfolio and clean energy standards), generation subsidies (such as feed-in tariffs or fee-bates), and traditional investment subsidies. In discussing these policies, we focus on four main questions:

(1) How do these policies create incentives for new investment?

(2) How do these policies affect the mix of generation technologies and electricity prices?

(3) What are the risks involved with each policy - and who bears them?

(4) Can we identify some policies as being clearly inferior to others?

This family of policies, which we refer to collectively as clean electricity policies, shares the primary goal of creating incentives to use cleaner electricity sources, thus enabling them to compete with dirtier sources when they would not otherwise be able to. This in turn encourages clean electricity manufacturing and R\&D. Supporters of these policies also tout ambiguous-and sometimes conflicting-environmental, employment, energy security, and international competitiveness benefits, complicating analysis and confounding efforts to identify an "ideal" policy.

Because of this, we do not advocate or even identify an ideal policy. Instead, our goal is simply to explain the basic policy choices and their economic implications. We have tried to avoid, where possible, alphabet-soup acronyms and excessive jargon. The policies themselves are not that complex when clearly described (as we have attempted to do), though the same often cannot be said for their wider implications, which are in some

\footnotetext{
${ }^{1}$ Center for Climate and Energy Solutions, 2012. Data accessed March 2013, last updated October 2012. www.c2es.org/node/9340.

${ }^{2}$ For details of the many specific clean electricity policies enacted at the state level, see the Database of State Incentives for Renewables and Efficiency, an ongoing project of the N.C. Solar Center and the Interstate Renewable Energy Council. Available at http://www.dsireusa.org/.
} 
Figure 1 Annual generation by energy source, 1998-2011

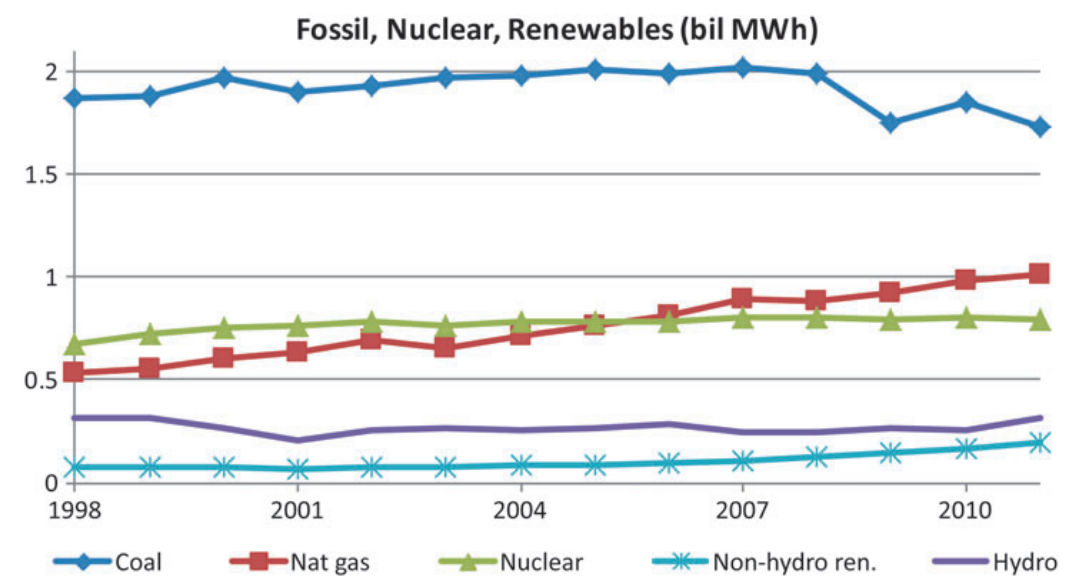

Source: Authors' calculations from Energy Information Administration (2013). ${ }^{3}$

cases the subject of continuing controversy among economists. Our conclusions are qualitative but we hope to help navigate quantitative assessments of particular proposals.

\section{Background of the U.S. Electricity Sector}

Before discussing the policies, we provide a brief background to the U.S. electricity sector, focusing on the contribution of clean electricity technologies to total generation, and on recent trends in investment and generation of all technologies.

Figure 1 shows annual generation for the major technologies used to generate electricity in the United States. For reference, annual generation has typically been about 4 billion megawatt hours (MWh). The figure shows that, historically, coal-fired generation has supplied about half of U.S. electricity consumption, although recently that share has fallen to about $40 \%$, at least partly because of low natural gas prices; natural gas-fired generation has grown steadily over these years. Because coal-fired generators typically have much higher emission rates than natural gas-fired generators, the shift from coal to natural gas has reduced carbon dioxide emissions.

Generation from nuclear and hydro facilities has been fairly stable during these years. Meanwhile, electricity generation non-hydro renewables, which includes wind, solar, biomass, geothermal, and other technologies, has increased steadily. Wind-powered generation accounts for most of this growth, and in 2011, non-hydro renewables accounted for about $5 \%$ of total generation.

Although figure 1 shows that non-hydro renewables account for a small fraction of total generation, figure 2 shows that natural gas is the only technology with greater investment than wind over the same time period. The figure plots the change in total capacity since 1998, and thus reflects both new investment and retirements. Natural gas capacity has increased by about 270 gigawatts (GW), compared to a total of about 1,000 GW of capacity in the entire U.S. power system. Low natural gas prices in the late

\footnotetext{
${ }^{3}$ Energy Information Administration, 2013. Data accessed March 2013. www.eia.gov/electricity/.
} 
Figure 2 Change in generation capacity from 1998 by energy source (GW)

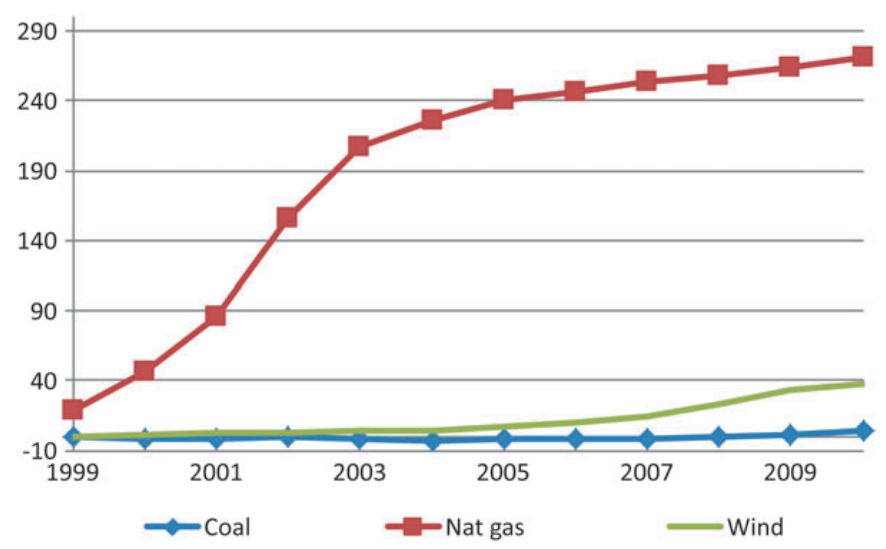

Source: Authors' calculations from Energy Information Administration (2013). ${ }^{3}$

1990s and 2000s, electricity market restructuring, and environmental policies probably explain this very large amount of investment. In contrast, investment in new coal plants has roughly offset retirements over this time period. Cumulative investment in wind-powered generators has been about $40 \mathrm{GW}$, which is far greater than investment in any other technology not included in this figure (by comparison, investment in solar-powered generators was about $2.5 \mathrm{GW}$ from 1998-2011). In short, non-hydro renewables account for a small but growing fraction of total electricity generation in the United States.

\section{Regulating Electricity Sector Carbon Emissions with the Clean Air Act}

The CAA is an old, lengthy, and diverse statute - it was created in its modern form in the 1970s, and was last substantially updated in 1990 - and forms the legal basis for a vast array of EPA and state regulation aimed at reducing air pollution and associated risks to health and welfare.

Until relatively recently, however, the CAA was not considered a viable tool for regulating GHG emissions. The U.S. Supreme Court's ruling in Massachusetts v. EPA (2007), that GHGs are pollutants within the CAA definition of the term, and subsequent EPA regulatory actions under President Obama have changed this view. The most significant EPA actions so far have been a formal "endangerment finding" in 2009 that triggers regulation, and significant steps to tighten vehicle fuel economy standards.

\section{Clean Air Act Carbon Regulation and the Electric Power Sector}

For the electric power sector, some important regulatory moves have been made, but the most significant steps are still in the future. For "stationary sources" like power plants, different CAA regulatory programs apply to new (and substantially modified or upgraded) sources and existing sources. 
The EPA's regulatory plan for new sources in the electric power sector is clear from proposed and implemented regulations, but its plan for existing sources is much less clear, though significant legal and economic research on regulatory options has suggested some possible options.

For new sources, the central regulatory program is "new source review" (NSR). Under NSR, new or substantially modified plants must undergo a case-by-case review by the EPA or state authorities. To obtain a construction permit, projects must show that they use the "best available control technology" (BACT). The NSR is a longstanding program, and firms building or modifying plants expect to be judged on whether they have implemented BACT for pollutants traditionally regulated under the CAA, such as sulfur dioxide and particulate matter. In a series of late-2010 rulemakings, the EPA expanded NSR to include the review of GHG emissions. Initially, only facilities emitting over 100,000 tons/year of $\mathrm{CO}_{2}$-equivalent GHGs were required to undergo review, though this threshold declines over time. Most electric power plants are above this threshold.

In 2012 the EPA also proposed new source performance standards (NSPS) for most types of power plants. The NSPS set objective, national standards of emissions performance for new or modified facilities in designated sectors (in CAA terms, "source categories"). In practice, these standards work as a floor that all facilities must meet-NSR/BACT review may impose stricter, but not weaker requirements. The proposed NSPS will, if finalized, apply to both coal and gas-fired power plants and would set a relatively stringent standard of 1,000 pounds of $\mathrm{CO}_{2}$ per megawatt-hour. Without carbon-capture-and-storage (CCS) technology, only gas plants can meet this standard. ${ }^{4}$ Since CCS is not commercially available, the standards would effectively ban the construction of new coal plants.

Even once the NSPS have been finalized, the large installed base of fossil fuel power plants will remain outside the scope of CAA regulation (except when plants undergo modifications that trigger NSR). The EPA, along with the states, does have authority under the CAA to regulate emissions from existing sources, however. Under a little-used provision of the CAA $(\S 111(\mathrm{~d}))$, the EPA and the states can implement existing-source performance standards (ESPS), broadly analogous to the NSPS. The EPA promised to issue these power-sector ESPS in a 2011 settlement agreement, but has since done almost nothing publicly to indicate when and how it will regulate. The state role in ESPS regulation is large, and any ESPS regulation will need to account for existing state approaches, including the clean electricity policies discussed in the next section. How this will occur is a major open question.

\section{Analysis and Implications of Clean Air Act Carbon Regulation}

The CAA has a reputation as a rigid, command-and-control regulatory statute that often leads to cost-ineffective regulations. There are notable exceptions, such as the sulfur dioxide trading program created by the 1990 amendments to the statute, but recent court decisions have undermined the flexibility of both this and other programs.

${ }^{4}$ The proposed standards do allow new plants to meet a higher standard of 1,800 lbs./MWh, if and only if they commit to installing CCS in the future. 
Figure 3 Climate policy options

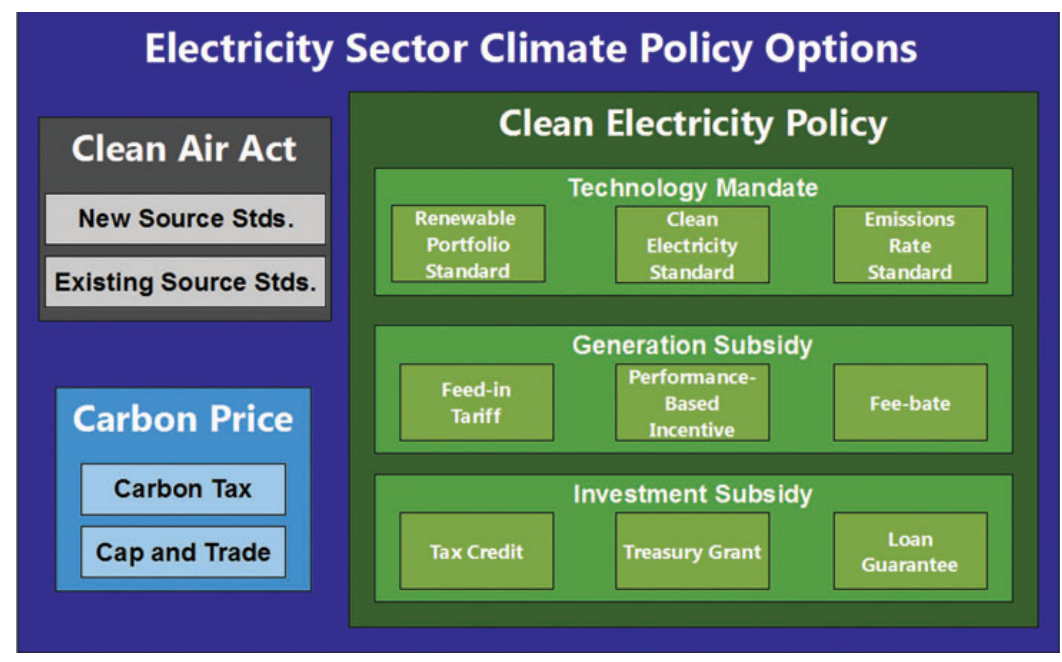

Nevertheless, there is strong evidence that CAA carbon regulation can be relatively flexible and cost-effective, at least over the short term. For the electric power sector, ESPS can likely incorporate significant flexibility. Legal analysis of the relevant provisions of the CAA leads most scholars to believe that the EPA can create (or, more accurately, can approve state decisions to create) flexible programs, including tradable standards, and possibly cap-and-trade or cap-and-trade-like systems for regulated sectors (Wannier et al. 2011). ${ }^{5}$ Economic analysis suggests that flexible ESPS approaches can achieve meaningful emissions reductions, on the order of $3 \%$ of national emissions from the power sector alone, relatively cost-effectively (Richardson et al. 2010).

Whether the EPA will adopt flexible approaches for regulating existing sources is an open question. It even remains uncertain whether the EPA will issue ESPS at all, though failure to do so would lead to litigation.

The ESPS, and indeed all CAA carbon regulations, can only directly reach the fossil-fuel powered plants that actually emit pollutants. Clean sources such as renewables and nuclear are not generally subject to CAA regulation. To the extent that CAA regulation increases the burdens on fossil generation, it can indirectly incentivize renewable investment. At least one ESPS proposal, from the Natural Resources Defense Council (Lashof et al. 2013), envisions more direct incentives by granting fossil emitters credits for investments they make in renewable generation (or demand-side energy efficiency), but it is unclear whether the EPA has the authority to implement such incentives (or to approve state attempts to do so).

If the goal is to increase investment in renewables, other policies beyond the CAA may be required. If sufficiently comprehensive, these policies may even be an effective replacement for a regulatory approach-however flexible-under the CAA.

\footnotetext{
${ }^{5}$ Even the Bush EPA took this position in 2005 when it attempted to use the same CAA provisions to create a national cap-and-trade system for mercury pollution, though this move was rejected by the courts for unrelated reasons.
} 
Figure 4 Technology mandates in the United States

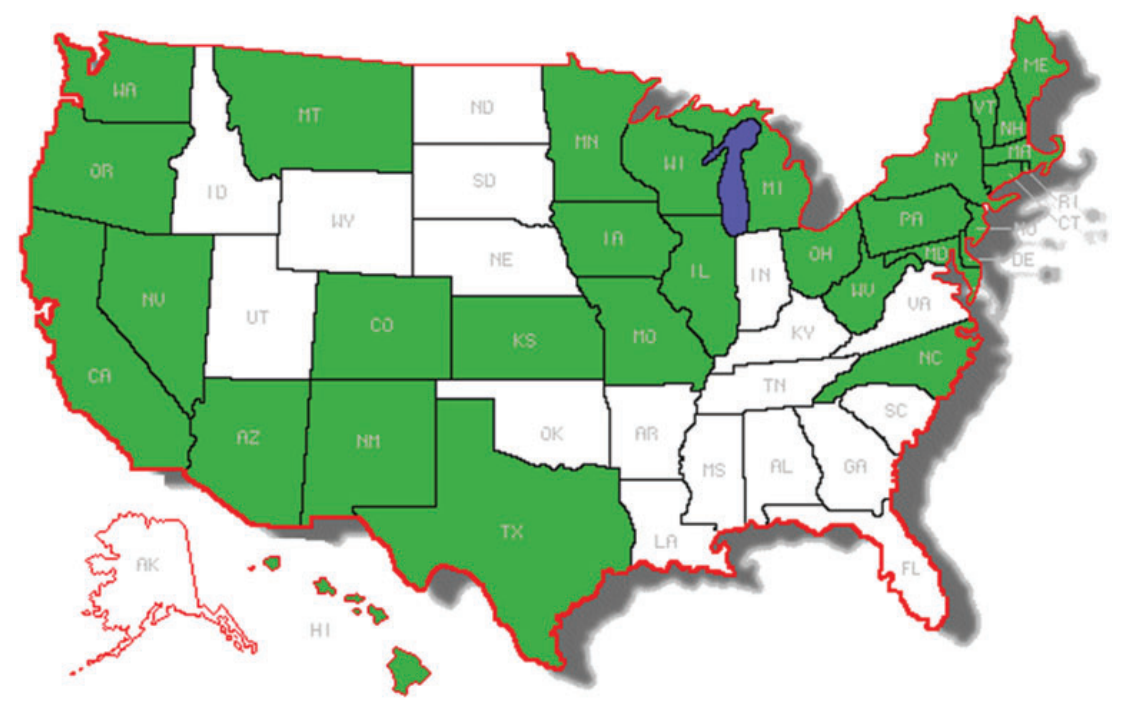

Source: Center for Climate and Energy Solutions (2012). ${ }^{1}$

Note: Shading indicates the presence of a technology mandate such as a renewable portfolio standard or clean electricity standard. States with technology goals that are not backed by fines for noncompliance, such as Utah, are not shaded. ${ }^{1}$ (For color, please see figure online.)

\section{Creating Incentives: Clean Electricity Policies Explained}

The history of CAA regulation is but one illustration of the long and close relationship between electricity generation and government. Policy-makers in other countries and at the federal and state levels have often enacted policies aimed at changing the technologies used to generate electricity. A classic example is the use of government subsidies for nuclear and hydroelectric projects. More recently, governments at all levels have favored renewable electricity sources, such as wind, solar, and geothermal, largely due to their environmental benefits. ${ }^{1}$ The policy tools for doing this - clean electricity policies - are our subject here. We divide these policies into three broad categories: technology mandates, generation subsidies, and investment subsidies (see figure 3, which shows policies discussed in this paper). This section describes how these policies work, and the next section discusses their effects on electricity markets.

\section{Technology Mandates: Renewable Portfolio, Clean Energy, and Emissions Rate Standards}

Many states aiming to promote the use of renewables have implemented policies requiring that a certain percentage of electricity generation come from renewable sources. ${ }^{1}$ These renewable portfolio standards mandate a desired outcome and leave firms to meet it how they see fit.

Utilities generate their own electricity or buy it from generators before selling it to consumers. Under most renewable portfolio standards, utilities are required to generate or purchase a set share of their electricity from renewable sources - or buy renewable energy credits from other utilities that exceed the standard to make up the difference. This creates a market (and a price) for renewable electricity. For renewable electricity generators, 
selling the credits increases the revenue they earn above the market price of electricity (Fischer 2010). ${ }^{6}$

As of 2011, more than 30 states had implemented or planned renewable portfolio standards or other technology mandates (see figure 4); however, the policies differ greatly in terms of their renewable targets, the sources they count as clean, and other details. For example, Ohio requires 25\% renewable generation by 2020 (including nuclear), while New York has targeted $30 \%$ (including existing hydroelectric) by $2015 .{ }^{1}$ As these examples illustrate, the definition of "renewable" and other design features vary across programs, and the actual share of generation from renewable sources may differ from the stated target. Some state markets are connected and allow interstate trading, but there is no federal renewable portfolio standard, despite several proposals in the U.S. Congress during recent years.

Some attention in Washington has turned to an evolution of the renewable portfolio standard with a broader scope, that is, the clean energy standard. In addition to renewables, a clean energy standard allows any electricity generator defined as "clean" to count towards meeting the goal. Not only renewables, but also nuclear and to some extent natural gas are treated as clean, with coal (minus carbon capture) alone classed as "dirty." We refer to a basic clean energy standard as one in which generators are given credits based on their technology and not their actual emissions rates. Former Senator Jeff Bingaman (D-NM) and, as noted above, President Obama (among others) have proposed clean energy standards; the president's proposal aims to generate $80 \%$ of U.S. electricity from clean sources by 2035 .

It is possible to tailor a clean energy standard even further by instituting an emissions rate standard (also known as a tradable performance standard). Under this scheme (e.g., Aldy 2011), a target emissions rate (a measure of a generators' efficiency) is set, and generators are given credits equivalent to that rate. If their actual emissions rate is below the target, generators will have extra credits they can sell to generators whose rates exceed the target (adjusted for the generators' relative size). This differs from a basic clean energy standard, which provides the same tax or subsidy to all generators of a given technology. Emissions rate standards can take advantage of the fact that emissions rates vary across generators of the same technology. For example, an efficient natural gas generator would earn more credits than an inefficient natural gas generator with an emissions rate standard, whereas the two generators would earn the same number of credits with a basic clean electricity standard. Of course, a clean electricity standard could be designed to credit each generator based on its actual emissions rate rather than based on its fuel source, in which case the clean electricity standard and emissions rate standard would differ in name only. Under an emissions rate standard, generators have an incentive not just to produce more electricity from clean sources, but also to produce electricity more efficiently.

\footnotetext{
${ }^{6}$ To simplify the discussion, we focus on generators in regions with competitive wholesale markets for electricity rather than in traditionally regulated regions, where the state imposes a set rate on the cost of providing service. Most investment in renewable generators has occurred in such regions in recent years. There are important differences in cost-of-service regions that are beyond the scope of this paper.
} 
Figure 5 Generation subsidies in Europe

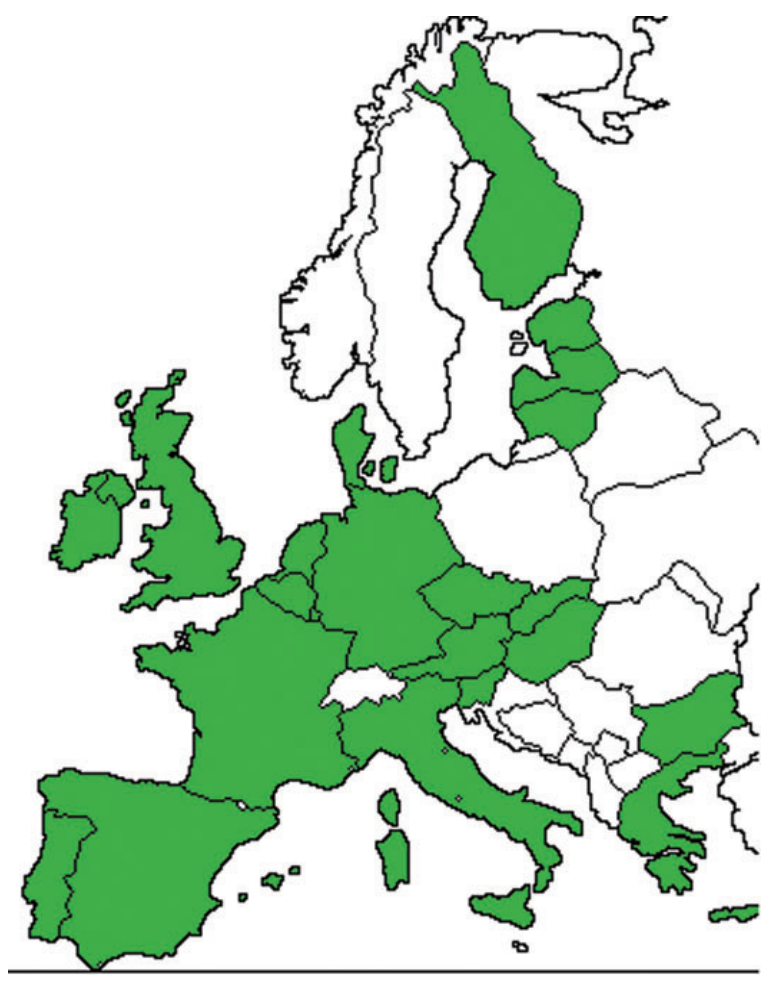

Source: Ragwitz et al. (2012).

Note: Shaded countries had some form of renewable energy generation subsidy in place as of 2012. (For color, please see figure online.)

\section{Generation Subsidies: Feed-In Tariffs, Performance-Based Incentives, and Fee-bates}

Technology mandates achieve their goals by setting a target quantity of clean generation or a target emissions rate. This allows the price of credits to fluctuate-if meeting the target is expensive, credit prices will rise. But there is an alternative approach: it is possible to set a price for clean electricity sources and let the market determine the quantity that will be supplied. This is analogous to the relationship between cap-and-trade, which sets a target quantity of emissions (the cap), and a carbon tax, which sets a target emissions price (the tax).

Generation subsidies target price rather than quantity (Fischer and Preonas 2010), and are substantially more popular in Europe than in the United States (see figure 5, which shows European countries that offer generation subsidies for clean electricity technologies).

Variants are somewhat cryptically called feed-in tariffs or performancebased incentives. In essence, these policies guarantee providers of specified kinds of electricity generation a subsidized price for the electricity they generate. Feed-in tariffs fix the per-unit price received by the renewable generator-generators receive a subsidy if the market price of electricity is below the guaranteed price. Under current policies and proposals, generators also forgo any additional revenue when the market price exceeds the guarantee. The regulator typically sets the feed-in tariff, and tariffs are often differentiated across technologies based on expected profits (Ragwitz et al. 2012). For 
example, Germany provides higher feed-in tariffs for solar generators than for wind generators to account for the higher costs of solar generators.

Performance-based incentives, on the other hand, subsidize each unit of electricity by a fixed amount, so that the generator earns the subsidy plus the market price of electricity for each kilowatt hour (kWh) of electricity generated. ${ }^{7}$ It is possible to give the same level of subsidy with either policy. For example, if the market price of electricity is 5 cents per $\mathrm{kWh}$, a feed-in tariff of 7 cents per $\mathrm{kWh}$ results in the same revenue for generators as a performance-based incentive of 2 cents per $\mathrm{kWh}$. Note that the equivalence breaks down as electricity prices change-the feed-in tariff offers a fixed price, whereas the performance based incentive offers a subsidy above the market price.

A major difference between generation subsidies and technology mandates is that the subsidies reduce generators' uncertainty about the revenue they will receive. With a feed-in tariff, generators have no uncertainty over future revenue. With a performance-based incentive, generators are uncertain how much revenue they will earn from the electricity market, but they know exactly how much they will receive from the government per kWh of clean electricity they generate. With a technology mandate, generators face uncertainty over both electricity prices and credit prices. In short, there is a clean electricity uncertainty principle-you can have certainty about the amount of renewable (or clean) electricity, or about its price, but not both at the same time.

Subsidies to clean electricity producers can be funded either from a general charge on all electricity bills or from general government revenues. In the case of a charge on electricity bills, the bill could separately itemize the charge or include it with other charges. For example, Germany has instituted generation subsidies supported by a general electricity rate charge, while Washington and other states have implemented them as tax credits, essentially supporting them out of general revenue. The federal production tax credit is a performance-based incentive, currently 2.2 cents per $\mathrm{kWh}$ but indexed to inflation, for wind and many other technologies in the United States; feed-in tariffs are much less common in the United States than in Europe. ${ }^{8}$

A fee-bate linked to generators' emissions rates is the generation subsidy analog of an emissions rate standard (Krupnick and Parry 2011). Just as an emissions rate standard is an extension of a clean energy standard, a feebate is an extension of a performance-based incentive. Under a fee-bate, a benchmark emissions rate is chosen, and a joint tax and subsidy are then imposed. All generators with emissions rates above the set level are taxed, and all generators below that level are subsidized, each in proportion to its emissions rate. Just like an emissions rate standard, a fee-bate encourages efficiency improvements and directly links the tax or subsidy to the emissions rate rather than aggregating by technology.

\footnotetext{
${ }^{7}$ In practice, the difference between a feed-in tariff and a performance based incentive is not so clear-cut. Some feed-in tariffs provide time-varying prices, as in California, or a flat subsidy over the market price. We use this terminology in this paper to distinguish between the two types of policies.

${ }^{8}$ Database of State Incentives for Renewables and Efficiency dsireusa.org.
} 


\section{Investment Subsidies}

Generation subsidies support generated electricity, thus encouraging investment by promising higher revenues. But it is possible to subsidize investment directly - doing so has been the traditional policy used to change the electricity mix. Perhaps unsurprisingly given their political appeal, classic investment subsidies have not been displaced by more flexible policies, such as technology mandates or generation subsidies. Almost all current federal policies to promote renewable electricity are investment subsidies, most notably a $30 \%$ subsidy for renewable investments. Loan guarantees and tax incentives, really subsidies in disguise, are also available. ${ }^{9}$

Investment subsidies have important disadvantages relative to other clean electricity policies, and are not generally favored by economists. This is partly because investment subsidies are not tied in any way to the economic or environmental value of the investment. Rather, they are typically offered as a fraction of a project's total capital cost. Wasteful investments are rewarded as much as effective ones - if a new wind turbine fails often, is poorly located, or is simply not efficient, it receives the same subsidy as a well-designed and well-sited turbine (Schmalensee 2009). In contrast, technology mandates and generation subsidies link their explicit or implicit subsidies to the amount of electricity actually generated. As a result, investment subsidies are generally less efficient than the alternatives, despite their long tradition as a policy instrument.

\section{Shaping the Electric Future: Effects on the Electricity Mix and Electricity Prices}

Figuring out the likely costs and benefits of clean electricity policies requires a close look at how they affect electricity markets. It is impossible to crown any particular class of policies as the most desirable, because outcomes depend on the stringency, timing, and scope of the policies, as well as on the makeup of the existing power system. Nonetheless, some general conclusions emerge.

\section{Basic Choices: Stringency, Time, and Scope}

First, it is useful to look at some basic design choices that are common to all clean electricity policies, and which have the power to greatly influence programs' costs, benefits, and effect. Fundamentally, these choices define the reach of the program. For technology mandates and price guarantees alike, these basic settings are stringency, timing, and scope. Clean electricity policies can be modest, requiring only a limited increase in clean electricity over a long period of time, or ambitious, requiring rapid and fundamental change to the electricity mix. The ambition of programs is defined by their stringency and compliance timing.

For technology mandates, stringency is usually equated with the percentage of electricity generation that the policy requires from clean electricity sources, either in absolute terms or compared to some baseline. For price

\footnotetext{
${ }^{9}$ In the last few years, investors have had the opportunity to receive a cash grant rather than a tax credit because of the difficulty of finding investors with sufficient tax liability to take advantage of the credit. Some projects are eligible for the performance-based incentive and investment tax credit or cash grant, but only one may be claimed.
} 
guarantees, stringency is the level of the guaranteed price. Higher percentages or higher guaranteed prices lead to more clean electricity.

Compliance timing for technology mandates is the pathway over time toward a particular level of target stringency. Price guarantees can also have a planned pathway; often the price guarantee decreases over time under the assumption that the cost, and therefore the required subsidy, of clean technologies also decreases.

The other fundamental element of a clean electricity policy is its scopethat is, what technologies are treated as clean? The difference between a renewable portfolio and clean energy standards is one of scope-indeed, a renewable portfolio standard can be viewed as simply a special case of a clean energy standard.

But the choice of scope can be more nuanced than simply which technologies to include. In most discussions of a clean energy standard, for example, technologies are credited according to the average level of carbon they emit. Cleanliness is defined relative to coal without carbon capture, and technologies with comparatively lower greenhouse gas emissions receive greater credits. A relatively simple clean electricity standard might, for each unit of electricity generated, provide coal with no credits, nuclear with one credit, and gas with a half credit (because it emits roughly half the greenhouse gases of coal for the same power output). Some proposals offer additional credits for favored technologies, such as solar. It is also possible to adjust the policy scope by excluding technologies (such as nuclear) or firms (such as small utilities) entirely. This has side effects - it can reduce the stringency of the policy, depending on which firms or technologies are excluded. Generation subsidies face similar choices about which technologies to subsidize, and at what levels.

\section{Effects on the Electricity Mix}

Once these fundamental design choices have been made and a clean electricity policy has been put into place, the policy will affect electricity markets. We focus on two such effects: changes to the mix of generation technologies, and changes in the price of electricity. We will first examine a renewable portfolio standard, then describe how other policies would have different effects.

Table 1 Taxes and Subsidies under Clean Electricity Policies

\begin{tabular}{|c|c|c|c|}
\hline & Coal Natural Gas & Renewables & Nuclear/Hydro \\
\hline Renewable portfolio standard & $\uparrow \uparrow$ & $d$ & $\uparrow$ \\
\hline Clean electricity standard & $\uparrow \uparrow \uparrow$ & 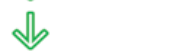 & $\downarrow$ \\
\hline Carbon price & 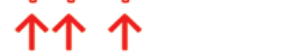 & $\leftrightarrow$ & $\leftrightarrow$ \\
\hline Generation or investment subsidy & $\leftrightarrow \leftrightarrow$ & & $\leftrightarrow$ \\
\hline
\end{tabular}

Note: The table assumes that new and existing generators of each type are treated similarly, that hydro power is not included in an RPS and does not receive investment or generation subsidies, and that under the clean energy standard natural gas is treated as dirty compared to the average, but not as dirty as coal. 
The purpose of clean electricity policies is to change the mix of electricity generation. However, different policies achieve this goal in different ways. In addition to changing the technologies used to generate electricity, some existing and proposed policies also include subsidies to energy efficiency. This relationship is complex, however, and we do not discuss it here.

Under a basic renewable portfolio standard, each generator receives a credit for each unit of renewable electricity it produces. When a utility purchases electricity from a renewable generator, it also purchases a credit from the generator at the prevailing market price. Therefore, the policy functions as an implicit subsidy for each $\mathrm{kWh}$ of electricity generation.

Conversely, the renewable portfolio standard implicitly taxes nonrenewable generation: for each unit of non-renewable generation that the utility purchases, it must also purchase a fraction of a credit to remain in compliance, since the utility's overall percentage of clean electricity must match the policy target.

These taxes and subsidies affect the mix of electricity generation. As table 1 illustrates, a renewable portfolio standard is a relatively blunt instrument-it taxes coal and gas, but does so indiscriminately; Gas gets no credit for being cleaner. This is different from what happens under a carbon price, which would explicitly or implicitly tax all generation in proportion to its $\mathrm{CO}_{2}$ emissions rate-with the higher emissions rate of coal leading to a higher implicit tax.

A more nuanced clean energy standard, in which technologies are credited in proportion to their average emissions rates, addresses this limitation; The higher emissions rate of coal leads to a greater implicit tax. A clean energy standard therefore will be generally less costly than a renewable portfolio standard per ton of emissions reduction, with costs that are closer to those from a carbon price.

This illustrates a general point about clean electricity policies - there is often a tradeoff between cost-effectiveness and complexity. By increasing complexity - tuning credits to the emissions rate-it is possible to target the most cost-effective technologies. But doing so might make the program harder to administer, and harder for politicians or the public to understand.

\section{Effects on Electricity Prices}

How clean electricity policies affect the electricity mix is important for determining how effective they are. But how the same policies affect actual electricity prices is a different question - and one that is politically critical.

Under a carbon price, electricity prices would increase, because coal and gas are explicitly or implicitly taxed (though revenues might be directed back to consumers to compensate for this). In contrast, with a technology mandate some technologies are implicitly taxed, but other technologies are implicitly subsidized. The subsidy leads to investment that, over time, tends to decrease prices. The overall effect on prices is ambiguous - in theory, electricity prices will not rise as much with a technology mandate as with an emissions price, and electricity prices may even decrease.

From a political perspective, lower electricity prices under a technology mandate are an advantage over a carbon price. However, they do reduce the policies' cost-effectiveness. The reason is that higher electricity prices stimulate energy efficiency investments - people will use less electricity if it is more expensive. The importance of this consideration depends on the net 
economic cost of energy efficiency investments, which may be anywhere from very high to negative (that is, worth doing even without considering the environmental benefits). Estimating these costs is an area of active research (e.g., Paul et al. 2011).

Generation subsidies are simpler to analyze than technology mandates because they subsidize renewable technologies without explicitly or implicitly taxing anything else. As a result, electricity prices unambiguously decrease. Likewise, investment subsidies lower the costs of generating clean electricity. However, we are only looking at electricity prices here-money for subsidies has to come from somewhere, raising overall costs to society. Electricity consumers will pay these costs, either directly if electricity use is taxed, or indirectly if general taxes fund the subsidies.

\section{Sharing Risk}

Even with a federal clean electricity policy, private players (and the government itself) must continue to make decisions about investment in different technologies. These decisions necessarily carry risk-depending on policy choices, risks to electricity generator investors' returns, risks to consumers of higher electricity prices, and/or risks to government of high expenditures.

Policy choices do affect who bears this risk. While different policies distribute risk differently, none actually eliminate it. A policy that reduces risk to one group increases it elsewhere. We discuss risk for investors, consumers, and the government in turn.

The most obvious risk-bearing group is the owners of electricity generators, who make large bets on future trends in the electricity market and government policy when they decide to build new generators. From the perspective of such investors, a feed-in tariff presents much less risk than a technology mandate or a performance-based incentive. By fixing the revenue a project earns per unit of electricity generated, the policy eliminates a large portion of the associated risk; only the risk associated with construction costs (or a future policy change) remains. Technology mandates do provide an implicit subsidy, but its value is uncertain because it depends on the market price of renewable or clean energy credits. The market revenue for a technology mandate or performance-based incentive may also be uncertain. ${ }^{10}$

Many in the clean electricity industry favor a feed-in tariff because of this risk-reducing effect. But this does not mean that such a policy is better from a societal perspective. A feed-in tariff does not eliminate risk, but merely transfers the risk to electricity consumers and perhaps the government (depending on how the policy is financed). For example, suppose that a feed-in tariff is offered for solar and that, due to technological breakthroughs, solar turns out to be more economical than other renewables. Because solar investment would have proliferated in the absence of the policy, the feed-in tariff would be very costly: electricity consumers would pay generators when they would have received the benefits of the solar electricity anyway.

${ }^{10}$ Uncertainty in the market electricity price depends on whether the renewable electricity is sold into a wholesale market or purchased by a utility, and the terms of the purchase agreement. 
Innovators also bear significant risks. One objective of clean electricity policies is to stimulate private $R \& D$ in clean electricity. If innovators face less risk, they will devote greater resources to innovation. Generally, investors will finance R\&D projects if they expect a fair return on the investment. For clean electricity, this return depends on the expected price paid for each clean electricity plant or component, as well as the quantity of electricity generation that is installed. Uncertainty over either the price or quantity results in less $R \& D$ because the $R \& D$ investment is riskier.

It is unclear whether a production subsidy or technology mandate does a better job of reducing these risks to innovators. As noted above, choosing between the two involves trading certainty about prices for certainty about quantity - and innovators would prefer both. ${ }^{11}$ There is little real-world evidence for which type of certainty is more important, and therefore which policy would better encourage innovation.

Consumers also bear some risk - if meeting technology mandate goals is more expensive than anticipated, consumers will face higher electricity prices. An alternative compliance payment is one approach to reducing this risk. This allows utilities to pay a fee rather than purchase renewable energy credits, effectively creating a ceiling for credit prices and reducing the risk to consumers. The downside is that since the utilities paying this fee continue using dirty electricity sources, the original clean energy target will not be met. By capping the price of credits and the amount of investment in new technologies, an alternative compliance payment also limits incentives to invest in R\&D and construction. Similar tradeoffs exist for price caps in cap-and-trade programs (such as California's)-indeed, anything that reduces risk by reducing the stringency of the policy has this effect.

Fiscal risk to the government is also important, particularly given widespread public concern about the federal deficit. As noted above, investment or generation subsidies carry some risk, since subsidies could be set too high. If these are financed by consumers via a charge on electricity bills, as is common in other countries, consumers will obviously bear the risks. But in the United States, subsidies are often implemented as tax credits or rebates. This places the risk of high subsidy costs on the government. Technology mandates do not impose a fiscal risk since their joint taxes and subsidies are implicit rather than explicit, with no government outlays needed. For example, a renewable portfolio standard does not require any government subsidies.

Like alternative compliance payments under a technology mandate, policy tools exist to reduce this fiscal risk. For example, a cap could be imposed on the amount of generation capacity that is eligible to receive the subsidy each year. This approach is often used for feed-in tariffs and could be extended to other generation and investment subsidies.

\section{Deeper Issues}

As the above discussions show, the effects of clean electricity policies are complex and difficult to predict. Efforts by economists to better understand these policies and their implications are underway (e.g., Palmer et al. 2011;

\footnotetext{
${ }^{11}$ Measures designed to reduce consumer risk, such as an alternative compliance payment, do not necessarily reduce risk to innovators because these measures increase uncertainty over quantity.
} 
Goulder et al. 2012); summarizing all of the important issues would be impossible. Nevertheless, it is worth looking at two issues identified by this research.

\section{The Problem of Existing Clean Electricity}

So far we have focused on how policy-makers decide to treat different types of new electricity generators. But a substantial amount of clean electricity is already available. Some of it is in the form of wind farms and solar facilities, but a much larger portion of U.S. electricity comes from other clean(er) sources: natural gas, hydroelectric, and nuclear.

The question arises: Should any of these generators receive support under clean electricity policies? For subsidies the answer is clearly no, because the investment decisions have already been made. But what about technology mandates? Superficially, the answer appears to be no. The aim of clean electricity policies is to create incentives to invest in new, clean electricity. Existing facilities need no such incentive: they have already been built, and particularly for renewables, hydroelectric, and nuclear, owners of these generators will probably operate them anyway because their fuel costs are very low or zero. In economic terms, their costs are mostly sunk. If only new clean power is counted in the program, there will be much more of it (assuming the target is the same)-and therefore more innovation and "green" jobs, if those are important goals.

But a problem arises. Recall that technology mandates implicitly tax dirty technologies and implicitly subsidize clean technologies, (here, "clean" refers to those technologies generating credits under the policy, while "dirty" refers to those that do not). If existing low-emission electricity sources do not create credits, they are treated the same as new high-emission sources - that is, as dirty generation. For example, many RPS programs do not count existing hydro plants as clean, in which case an electricity retailer must purchase RPS credits when purchasing electricity from such a hydro plant; the cost of the credits represents the implicit tax. The implicit taxes can create perverse outcomes. Replacing existing clean electricity plants with similarly clean new sources would be rewarded by the program, but is wasteful if the goal is to reduce $\mathrm{CO}_{2}$ emissions at low cost. In other words, the incentives for new clean electricity to replace existing clean electricity would be just as strong as those to replace dirty coal. Hydro- and nuclear plants have such low fuel costs that they are not likely to be replaced even if they are implicitly taxed by a clean electricity standard that treats them as dirty by only counting new generators as clean. But that may not be true for natural gas-fired generators. To avoid these perverse outcomes, clean electricity policies should provide at least some credit to existing clean generators, particularly natural gas, at least if new gas receives credits - something a $\mathrm{CO}_{2}$ price implicitly does, by treating new and existing generation sources equally.

\section{More Thoughts on the Electricity Mix: Markets, Technologies, and Investor Incentives}

An often underappreciated feature of the market for electricity is that both the productivity of different generating technologies and the demand for electricity vary over time. Solar is useful only during the day (unless electricity can be cheaply stored), while winds often blow harder at night. Demand is highest during the day and in the summer, as are prices, since 
relatively high marginal cost generators are brought online to meet that demand. For sake of simplicity in the above discussions, we have ignored the implications of these factors for clean electricity policies.

However, such factors are important for understanding the policies and their effects on investment in different generating technologies (Joskow 2010). Investors will always seek to maximize their profits - that is, the revenue they expect from a project, minus its cost. If electricity prices were constant, then investors would simply seek to minimize cost by building the lowest-cost projects - which for renewable electricity in the United States usually means wind.

But since electricity prices do vary over time, projects that have a higher initial cost, but which generate more electricity when it is expensive, will have higher associated revenues. These projects generate higher value, and more needed electricity. Investors, seeing this larger expected revenue stream, will consider building such higher-cost projects. This partially explains investment in solar generation, which currently has higher initial costs than wind.

Imposing a renewable portfolio standard or a performance-based incentive has relatively little effect on these investor decisions, since it simply creates a subsidy (real or implied) that is equal for all renewable generators. The result, unsurprisingly, is greater investment in renewables, but investors still look to maximize profits by comparing projected cost with expected revenues, and these revenues continue to vary with electricity prices.

Under a feed-in tariff, on the other hand, the influence of electricity prices on expected revenues from renewables is blunted, and investors make different decisions. Recall that a feed-in tariff guarantees renewable generators with a set revenue for every unit of electricity they generate. The difference between this level of revenue and the market price of electricity is made up by a subsidy, which will vary depending on that price. With revenues guaranteed to be the same for all renewable technologies, cost is the only factor in investors' profit-maximizing decisions. In other words, a feed-in tariff eliminates one type of risk for investors. The degree to which investment patterns differ under a feed-in tariff depends on how great of a mismatch there is between the lowest-cost technologies and those that are productive when prices are highest, something which may change over time due to innovation. In practice, a feed-in tariff means greater investment in wind at the expense of other renewables, at least with current technology.

This difference in investors' decisions matters (Fell and Linn 2012). Electricity generated when market prices are high is more valuable, so policies that encourage investment in sources that are productive at that time (or, more accurately, policies that leave the market's incentives to build such sources intact) will likely be more cost-effective. Put differently, renewable portfolio standards or performance-based incentives are likely to lead to investment in renewable generation that has a higher market value than that under a feed-in tariff; that market value reflects a greater usefulness to society.

It is also possible to tailor policies to promote specific technologies regardless of their underlying costs by rewarding the favored technologies with additional credits or subsidies. This is useful if one considers it wise to diversify investments across different clean technologies, though it does also result in higher costs for the same amount of clean generation. 
Finally, if the goal is to promote renewable electricity for its own sake, as opposed to reducing overall emissions, a clean energy standard is less effective than alternatives since it does not specifically target renewables. For example, if natural gas prices are low, a clean energy standard could cause a large-scale switch from coal to natural gas generation, but little investment in renewables. Very different levels of renewable generation for the same level of emissions reductions could emerge under a clean energy standard compared to a renewable portfolio standard.

\section{Conclusions}

\section{What We Know}

Clearly, the implications of electricity sector carbon policy can be complex. Other than a carbon price, there are two primary pathways to substantially reducing carbon emissions - regulation under existing law, and clean electricity policies.

At the federal level, regulation under the Clean Air Act is the primary tool. For new power plants, its implications are relatively clear-an apparent ban on the construction of new coal unless CCS technology becomes economical. For existing sources, the path is much more ambiguous. The EPA will likely soon propose performance standards for existing sources, but it is unclear when these standards will take effect, how stringent they will be, and to what extent the EPA will make them flexible and, therefore, more cost-effective. States will play a major role in this process.

While the federal wind subsidy persists despite rumors of its demise, states have also been the leaders in implementing clean electricity policies. In recent years there has been some indication of a federal clean electricity standard, but no bill has come close to passing.

In the meantime, different jurisdictions use different tools, and neither politics nor efficiency seem to dictate that any particular option be adopted at the federal level (if we are to have a federal policy at all). Nevertheless, economic analysis of these policies provides certain core insights.

1) The clean electricity uncertainty principle.

It is possible to be certain about the price that clean electricity generators receive (by using a production subsidy), or the quantity of clean electricity they supply (by using a technology mandate) - but not both.

2) Investment subsidies are generally a poor choice.

Primarily because they do not distinguish between good and bad investments, investment subsidies are much less cost-effective than other options.

3) Comparing a clean energy standard and renewable portfolio standard, there are tradeoffs between cost-effectiveness and complexity.

More complex policies can target the cleanest and/or most cost-effective technologies, but may be harder to administer or understand.

4) Consumer electricity prices could fall under clean electricity policies or at least increase less than under a carbon price.

In theory, a production subsidy and possibly a technology mandate causes electricity prices to decrease. Even if a technology mandate leads to higher prices, the price increase will be smaller than with a simple carbon price.

5) Excluding existing clean electricity creates perverse incentives. 
If existing clean electricity sources are included in a policy but are not given credits or generation subsidies, they are effectively treated as dirty. The resulting implicit tax may cause some low-emissions generators, particularly natural gas-fired, to shut down, and overall emissions may not fall.

6) Different clean electricity policies cause different mixes of investment in renewable electricity.

Feed-in tariffs lead to investment in the lowest-cost renewable technology, but renewable portfolio standards and performance-based incentives lead to investment in the most profitable technology.

\section{What We Do Not Know}

The answers to other questions about the impact of clean electricity policy choices remain unclear. Three seem particularly important.

1) What form will the CAA regulations take?

The EPA has taken significant steps toward regulating new emissions sources in the power sector. If proposed NSPS are finalized, they will effectively ban new coal construction without CCS. But in the short- to medium term, the opportunities for reducing emissions are far greater from existing than from new sources. Here, much less is known about the EPA's regulatory approach. Legal and economic analysis indicates that the agency, along with states, does have the authority to regulate existing sources. But the timeline for this regulation, its scope, its stringency, and its form are all unknown. Existing state programs will undoubtedly play an important role, but whether they are compatible with EPA regulation and the legal limits of the CAA is unclear. Real legal and political risk exists for any approach the EPA takes.

2) It is unclear which policy would be most effective at encouraging innovation in clean electricity.

Policy-makers can choose between certainty about the price that generators receive for clean electricity and the quantity they will supply. However, it is unclear which type of certainty would better promote innovation. It is quite possible that investment subsidies for basic R\&D, as opposed to clean electricity policies, would have the greatest impact on innovation; if researchers are not able to capture the benefits of their breakthroughs, policies that increase the demand for clean electricity technologies will not have much effect on innovation (Fischer and Newell 2008).

3) Effects on employment - "green jobs" - are not straightforward.

One popular claim is that clean electricity policies could create more jobs. But is is not clear whether technology mandates, production subsidies, or investment subsidies would lead to job growth, much less which of the three would do the most. Technologies differ in terms of their labor intensity. If adding jobs is the goal, more labor-intensive technologies should be promoted at the expense of more capital-intensive ones. Adding more jobs, however green, does not necessarily lead to greater environmental benefits. As noted above, if credits are denied to existing sources of clean electricity under a technology mandate, new clean electricity sources might be built only to replace those existing sources. This is inefficient from an emissions perspective, but would undoubtedly create nominally-green construction jobs (i.e., nominally green in the sense that the jobs may cause emissions themselves, such as particulates associated with construction). 


\section{Lessons for Policy-makers}

In theory, clean electricity policies are second-best to a carbon price. Among other limitations, they lack a price's simplicity, are probably more costly, and are harder to link to other sectors to create an economy-wide (and therefore less costly) carbon policy. But the political reality is that a carbon price appears to be off the table for at least the near future. Moreover, it is important to compare policy options with each other rather than with ideal chalkboard alternatives - and as the Waxman-Markey Bill of 2010 illustrates, a carbon price itself would require compromises, carve-outs, and concessions, making it more complex and probably less efficient. And from a (somewhat cynical) political standpoint, clean electricity policies have several advantages over a carbon price: compliance costs are harder to observe, the policies are less likely to increase electricity prices, and it is not as easy to characterize them as a tax (or cap-and-trade, for that matter).

But the politics of clean electricity policies also make them harder to evaluate. Comparisons between different options are complicated by the fact that goals are unclear and sometimes at odds. Is reducing emissions the aim? Advancing certain favored technologies? International competitiveness? Jobs? If the goal is to reduce emissions, the best approach is to tailor a policy's subsidy or tax to emissions. But clean electricity policies are politically viable in large part due to their chameleonic character. A policy that is framed as purely a climate policy, rather than an energy, security, or jobs policy may be much harder to pass.

Clean electricity policies are in widespread use already in a number of U.S. states and around the world. Policy options have important differences, with significant impacts on the future electricity mix, electricity prices, and other important considerations. Navigating this complexity to reach an efficient and effective policy requires policy-makers, as always, to make smart choices.

\section{References}

Aldy, J.E. 2011. Promoting Clean Energy in the American Power Sector. Discussion Paper 2011-04, The Hamilton Project, Washington, DC.

Fell, H., and J. Linn. 2012. Renewable Electricity Policies, Heterogeneity, and Cost Effectiveness. Working Paper Series 2012-07, Colorado School of Mines.

Fischer, C. 2010. When Do Renewable Portfolio Standards Lower Electricity Prices? Energy Journal 31(1): 101-20.

Fischer, C., and R. Newell. 2008. Environmental and Technology Policies for Climate Mitigation. Journal of Environmental Economics and Management 55(2): 142-62.

Fischer, C., and L. Preonas. 2010. Combining Policies for Renewable Energy: Is the Whole Less Than the Sum of Its Parts? International Review of Environmental and Resource Economics 4(1): 51-92.

Goulder, L.H., M.A.C. Hafstead, and R.C. Williams, III. 2012. General Equilibrium Impacts of a Federal Clean Energy Standard. Unpublished working paper.

Joskow, P. 2010. Comparing the Costs of Intermittent Dispatchable Electricity Generation Technologies. Working Paper WP-2010-013, MIT Center for Energy and Environmental Policy Research.

Krupnick, A.J., and I.W.H. Parry. 2011. Is a Clean Energy Standard a Good Way to Move U.S. Climate Policy Forward? Issue Brief 11-04, Resources for the Future, Washington, DC. 
Krupnick, A.J., I.W.H. Parry, M. Walls, T. Knowles, and K. Hayes. 2010. Toward a New National Energy Policy: Assessing the Options. Washington, DC: Resources for the Future, Washington, DC.

Lashof, D.A., S. Yeh, D. Doniger, S. Carter, and L. Johnson. 2013. Closing the Power Plant Carbon Pollution Loophole: Smart Ways the Clean Air Act Can Clean Up America's Biggest Climate Polluters. NRDC Report R: 12-11-A: Washington, DC.

Massachusetts v. EPA, 549 U.S. 497 (2007).

Palmer, K., A. Paul, and M. Woerman. 2011. Federal Policies for Renewable Electricity. Energy Policy 39(7): 3975-3991.

Parry, I.W.H., and R.C. Williams, III. 2011. Moving U.S. Climate Policy Forward: Are Carbon Taxes the Only Good Alternative? Discussion Paper 11-02, Resources for the Future, Washington, DC.

Paul, A., K. Palmer, and M. Woerman. 2011. Clean Energy Standards for Electricity: Policy Design Implications for Emissions, Supply, Prices, and Regions. Discussion Paper 11-35, Resources for the Future, Washington, DC.

Ragwitz, M., C. Klessman, and G. Resch. 2012. Recent Developments of Feed-In Systems in the EU - A Research Paper for the International Feed-In Cooperation. Available online at http://www.feed-in-cooperation.org/wDefault_7/content/ research/index.php.

Richardson, N., A. Fraas, and D. Burtraw. 2010. Greenhouse Gas Regulation under the Clean Air Act: Structure, Effects, and Implications of a Knowable Pathway. Discussion Paper 10-23, Resources for the Future, Washington, DC.

Schmalensee, R. 2009. Renewable Electricity Generation in the United States. Working Paper WP-2009-017, MIT Center for Energy and Environmental Policy Research.

Wannier, G.E., J.A. Schwartz, N. Richardson, M.A. Livermore, M.B. Gerrard, and D. Burtraw. 2011. Prevailing Academic View on Compliance Flexibility under § 111 of the Clean Air Act. Discussion Paper 11-29, Resources for the Future, Washington, DC. 